\title{
Study on the Present and Focus of Ability System for Vocational Teacher
}

\author{
Guiying Guo Qinglong Zhan
}

School of Informational Technology, Tianjin University of Technology and Education, Tianjin 300222, China; Teaching Ability and Professional Capability Research Center,

Tianjin Key Research Base for Humanities and Social Science, Tianjin , China

\begin{abstract}
This paper analyzes the current situation of ability system for vocational teacher, and refines the research focus and development trends. The main features of the current situation are isolated studies of various abilities, obvious bias, less empirical research and more theoretical studies. The main focus of the research are teaching ability, the ability of using IT, and the ways of training for vocational teacher. This article also presents research trends of ability system for vocational teacher, which are the architecture model, emphasis on teachers' ability of psychological health education, and the establishment of the evaluation system for vocational teachers' abilities.
\end{abstract}

Keywords: Vocational teacher; Ability system; Double qualified teachers

\section{Introduction}

The abilities of teachers are the collection of performances. The performances which implicit in the education and teaching activities affect the effectiveness and quality of the education and teaching activities, and determine the implementation and completion of the education and teaching activities. Teacher abilities system is the reasonable integration and special development of various abilities, and it also is comprehensive quality which development in practice, and reflect requirements of the teachers' professional activities. The second half of the 20th century, the teacher abilities to cultivate specialization has become the main trend of the global reform of teacher education, and many developed countries and regions take their responsibility to promote the development of teacher abilities in the legal, economic, policy, and also attache importance to the abilities development of vocational teachers. Face to the teaching contents and requirements of vocational education, vocational teacher ability system is build on its own characteristics. This paper first embarks on the results of previous studies, and analyzes the present of ability system for vocational teacher, then explores the focus of ability system for vocational teacher, finally put forward the trends of the future development and research.

\section{Analysis of present study of ability system for vocational teacher}

Ability system for vocational teacher can be shown in Figure 1.

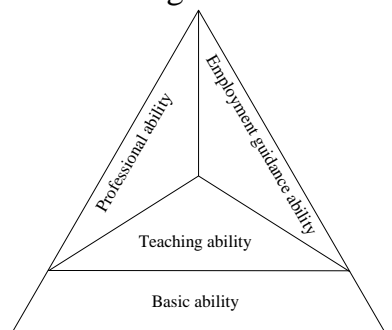

Fig.1. Ability system for vocational teacher 
Researching the development status of ability system for vocational teacher is the necessary process of understanding the overall situation, and this is the basic conditions of follow-up study for the field. From the analysis of existing researches, the study of ability system for vocational teacher has the following characteristics.

\subsection{Individual Studies of Various Abilities}

There are a large number of researches for vocational teachers' abilities form multiple angles, for example, in the realm of the pursuit, philosophical perspective, individual professional development, groups professional development, abilities building connotation, and effective ways are all discussed. However, these results and understanding have not formed an organic whole and frame system, and it makes slow progress of this research, and difficult to have a qualitative leap. A complete ability system for vocational teacher should be the first to break the subject.

\subsection{Focuses of Studies}

The ability system for vocational teacher contains various abilities. Obviously, researchers are more concerned about the teaching ability, and the results of research in this area are the largest. The expand abilities have been researched more, and these abilities include innovation ability, ability to cooperate, lifelong learning ability. Slightly less basic abilities for research include teacher observation, memory, imagination, and interpersonal skills, hands-on skills and language skills. Least studied are the ideological and psychological education ability. When teachers complete the process of teaching activities, it is also reflect the status of various abilities. Therefore, fully development of teachers' abilities are the basis to complete their work better, and the study of vocational teacher ability should be comprehensive.

\subsection{The Fewer Empirical Research and More Theoretical Research}

The majority of ability system for vocational teacher research focused on the theoretical construct, this issue needs systematically studied. Ability system for vocational teacher is a dynamically changing architecture, with the advancement of technology, the ability of education technology applications be incorporated into teacher ability system. The view of the world changes the ways and means of education, as well as students. In order to better know the upgrade requirements of facilities, the study should be made as a high-rise buildings, and escalating its various facilities. The building of ability system for vocational teacher to rely on in-depth and meticulous research, rely on close contact with teachers and students to build up. Therefore, we should strengthen the empirical research, and use practice to verify theory, this should be a virtuous cycle.

\subsection{Constantly Enrich of the Connotation of Ability System for Vocational Teacher}

Researchers have payed attention to vocational teacher ability system category, and constantly enriched the connotation of ability system. From an ordinary teacher abilities to rise to the "Double Qualified Teachers", it added to the teacher occupation abilities requirements, and some scholars put forward "Four Qualified Teachers" of teacher team construction. The "Four Qualified Teachers" including teachers' moral, professional knowledge, practical skills and employment guidance ability. It greatly expands the connotation of teacher ability system and the research field of vision, and guides the direction and focus of research. 


\section{Research focus of ability system for vocational teacher}

Currently, the researchers of ability system for vocational teacher mostly concentrate in college, and the less of vocational teachers to participate in. It makes the theoretical research is more, and most studies of individual ability focus on the instructional design, educational technology application ability, teaching organization and scientific research ability. That's all teachers should have in common abilities but not special abilities for vocational teachers. The following is the detailed discussion of these aspects. The research areas of ability system for vocational teacher can be shown in Figure 2.

\subsection{Instructional Ability}

Instructional ability is a basic ability requirement for teachers, and vocational teachers are no exception. Instructional ability also becomes the old traditional project of teacher abilities in the research. The research depth is more prominent, such as teaching design ability, and the ability of organization and management. Instructional ability is the important constituent of teacher ability system, it needs continue to be more thorough research.

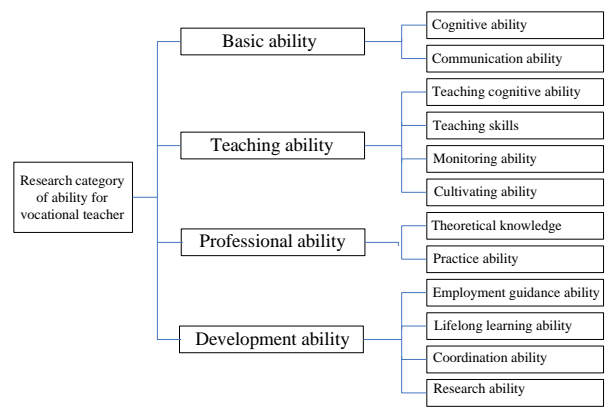

Fig.2. The research areas of ability system for vocational teacher

\subsection{Ability of Educational Technology}

Education technology ability is development with the progress of science and technology, and is the new requirements to teacher abilities. Its development and implementation is in line with the state development and planning. For this part of the study is not only reflected in the study of text materials, but also in the implementation and applications. Vocational teacher training has this field training courses in many countries. The curriculum contains knowledge which often can be used in daily teaching. Through a number of information technology application can enhance the effect of classroom, improve the efficiency of management, so the ability of educational technology has received much attention.

\subsection{Ways of Training}

The training modes of vocational teacher are different from different countries. In our country, the training mode is continuous growth with the experience and development, and the training is mainly focus on the schoolenterprise cooperation, technical services, technical research, teaching reform, and pay attention to implementation. The escorts of development for vocational teacher abilities are management system, incentives and performance evaluation system.

\section{Trends of Ability System for Vocational Teacher}

Through analysis of the status quo and survey of the focus of ability system for vocational teacher, the author put forward the following research and development trends of ability system for vocational teacher, in order to meet the development of vocational education better. 


\subsection{Establishment of Vocational Teacher Ability System Model}

Establishment of vocational teacher ability system model can laid the theoretical foundation of vocational teachers research for follow-up study. At present the research of vocational teacher abilities in our country does not form a system, which makes the advancing of research slow and difficult. Establish vocational teacher ability system model is beneficial to exploring the approach and strategy of teacher ability development, and can rich its theoretical connotation. The building of related approaches and Strategies can enrich the theory system of teacher abilities, develop the theory knowledge node, increase knowledge of choroid depth, and guide more practical study. Constructing vocational teacher ability system is conducive to the construction of relevant system. Vocational teacher ability system is the basis of developing training plan and rules. Establishment of vocational teacher ability system model will advance system and standard construction.

\subsection{Emphasis on Psychological Health Education}

The majority of vocational school students usually have a poor academic performance and violation of school regulations with higher frequency compared with children of the same age. Which increases the difficulty of teaching and the day-to-day management, it need taking more time to maintain discipline and emphasized on school rules. Therefore, these students are also likely to lose teachers' confidence for them. These students have the attitude of "smash a pot to pieces just because it 's cracked" , and the self-esteem and inferiority complex fusion in their hearts. This requires vocational teachers pay more attention to the psychological health education, which can help students building confidence of overcome challenges, so that they can feel their own progress, and continue to get recognition and encouragement, and mobilize students' enthusiasm to learn, and also the teacher can become students' close friends.

\subsection{Establishment of Evaluation System for Vocational Teacher Abilities}

Establishment of vocational teacher abilities evaluation system boost teacher abilities development. Vocational teacher abilities evaluation system is still a weak link of the research on the development of vocational teacher abilities in our country. The evaluation system can make the teacher to explicitly know their own abilities development, and also have a definite object on ability training and exercise, and to develop more clear study plan. Vocational teacher abilities evaluation system needs to provide the proposal of teachers training strategy and its pathways, and point out the teacher abilities training direction and the learning method, and to facilitate teachers' self-evaluation and improvement. Such abilities evaluation system can give powerful aid for teacher development.

\section{Conclusion}

Vocational education is the "cornerstone and framework" of the development of contemporary China, but also the huge boost power of national economy. With the expansion of the scale of vocational education, the building of vocational teacher abilities system should become the focus of the study, and get rid of the tendency which applies and transplants the outcome of the general education. Good environment should be established for the development of ability system for vocational teacher. 


\section{Acknowledgment}

This study was part of the research project of "The Study of Ability System for Vocational Teacher" by the grant from the Tianjin Philosophy and Social Sciences Plan (TJJX12-141). And supported by Teaching ability and professional capability Research Center of Tianjin key research base for humanities and social science.

\section{References}

[1] Lizhen Wang, Hai Lin, Cungen Ma, Weiping $\mathrm{Hu}$, The research situation and trend analysis of teachers' ability in the last thirty years $[\mathrm{J}]$, Theory and Practice of Education, 2012,(10):38-42
[2]Kewen Sang, "Four Qualified Teachers" waiting for us construction[J], Journal of Bayinguoleng college of vocational and technical, 2012,(1):7-8

[3] Ning Ma, Geng Chen, Junsheng Liu, Jie Ding, Shengquan $\mathrm{Yu}$, Study on "National Educational Technology Guides for Teachers in Higher Education"[J], Journal of Distance Education, 2011,(6):3-6

[4]Qiqing Liu, Competence Framework for VET Teachers in European Union and Their Inspiration[J], Chinese Vocational and Technical Education, 2011,(15):72-77

[5]Rui Jiang, Jianju Wu, Panhui Jiang, A comparative study on training of domestic and foreign Vocational teachers' abilities[J], Market modernization, 2011,(8):139-141

[6] Xiaoling Ma, Rong Wang, Lu Li, Jijun Wang, Meifeng Liu, Study on informational technology teachers ability structure[J], China Educational Technology, 2011,(3):12-16 